\title{
Highly Populated Turn Conformations in Natively Unfolded Tau Protein Identified from Residual Dipolar Couplings and Molecular Simulation
}

\author{
Marco D. Mukrasch, Phineus Markwick, Jacek Biernat, Martin von Bergen, Pau \\ Bernado, Christian Griesinger, Eckhard Mandelkow, Markus Zweckstetter and Martin \\ Blackledge
}

\section{Supporting Information}

Reference 44 in full :

44) Case D.A.; Darden, T.A.; Cheatham III T.E.; Simmerling, C.L.; Wang, J.;

Duke, R.E.; Luo, R.; Merz, K.M.; Wang, B.; Pearlman, D.A.; Crowley, M.;

Brozell, S.; Tsui, V.; Gohlke, H.; Mongan, J.; Hornak, V.; Cui, G.; Beroza, P.;

Schafmeister, C.; Caldwell, J.W.; Ross, W.S.; Kollman, P.A. 2004,

AMBER 8, University of California, San Francisco 
Figure 1. Comparison of RDCs measured in Tau K18 aligned in uncharged polyacrylamide gel (thin line) and bacteriophage (thick line).

$\mathrm{D}(\mathrm{Hz})$

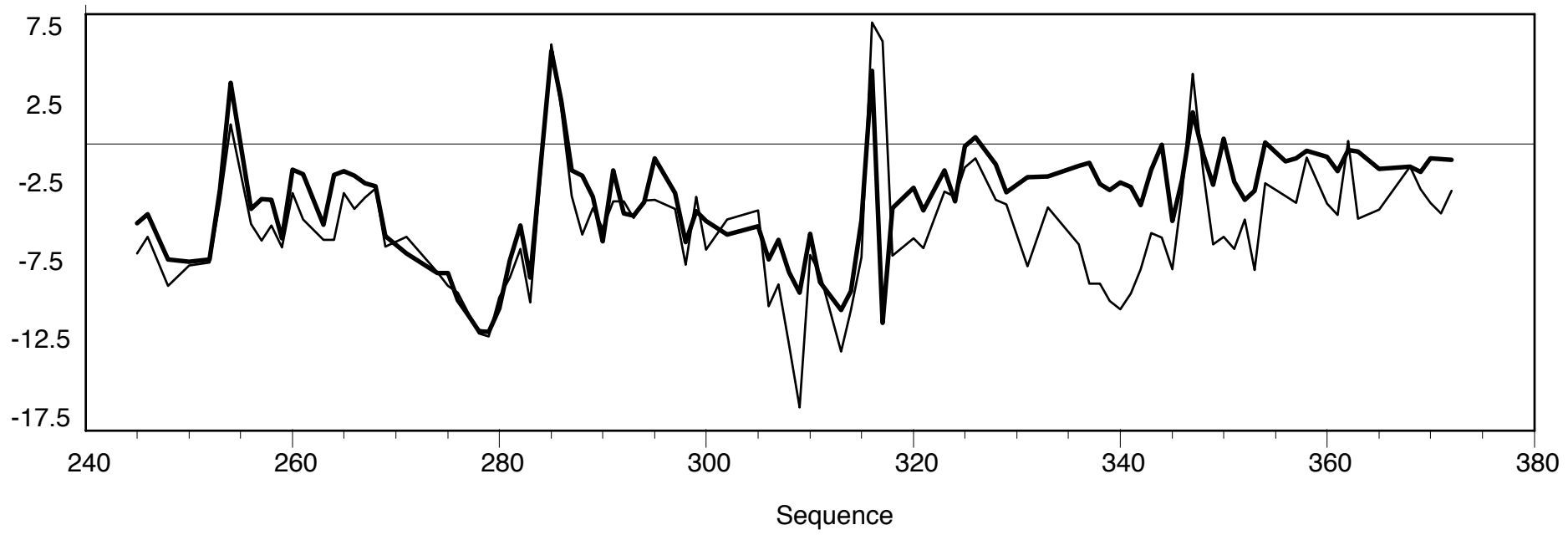


Figure 2.

Prediction of ${ }^{\mathrm{N}} \mathrm{H}-\mathrm{N}$ RDCs from Tau K18 construct using the combined statistical coil/ Molecular dynamics model (thin line) compared to experimental values (thick). Conditions as in figure 6 , except that additional beta sheet propensities predicted in a previous study were not included.

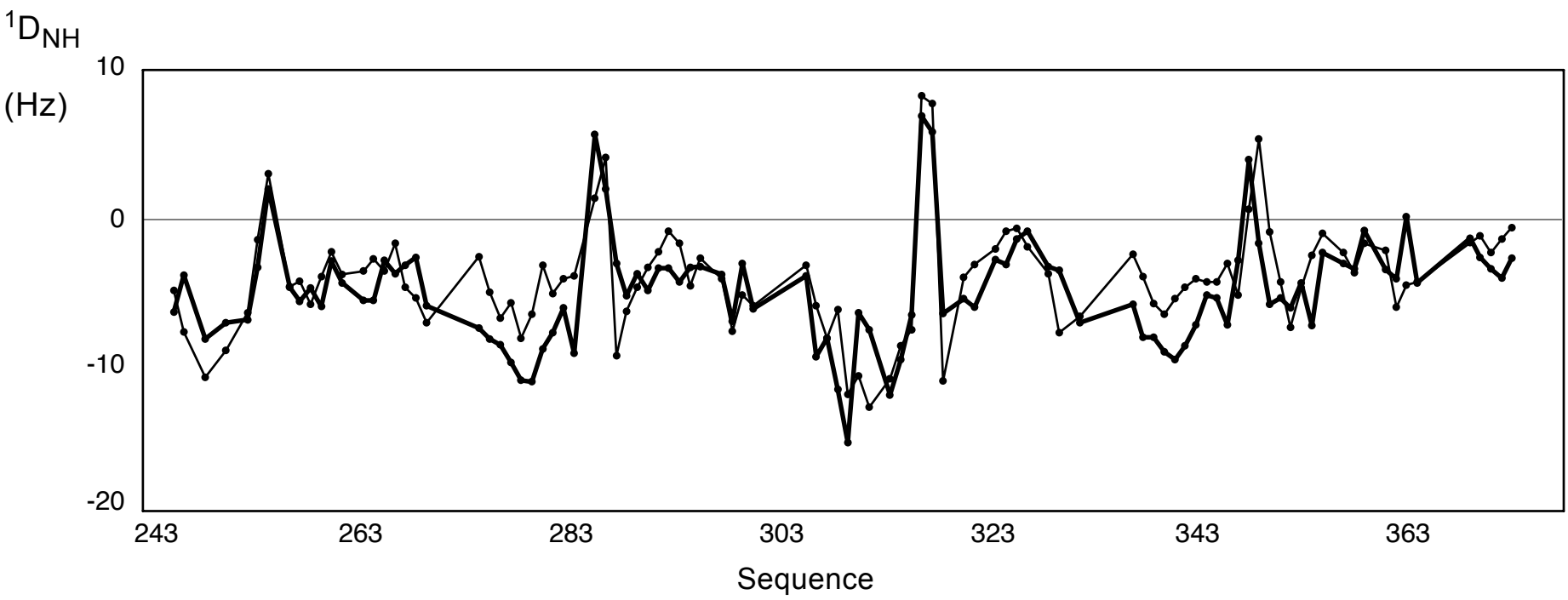


Figure 3.

Comparison of measured NH RDCs from K18 dissolved in standard buffer (black) and 8M Urea (red). Both were aligned in Polyacrylamide gel. Standard buffer refers to the experimental conditions described in the Methods section.

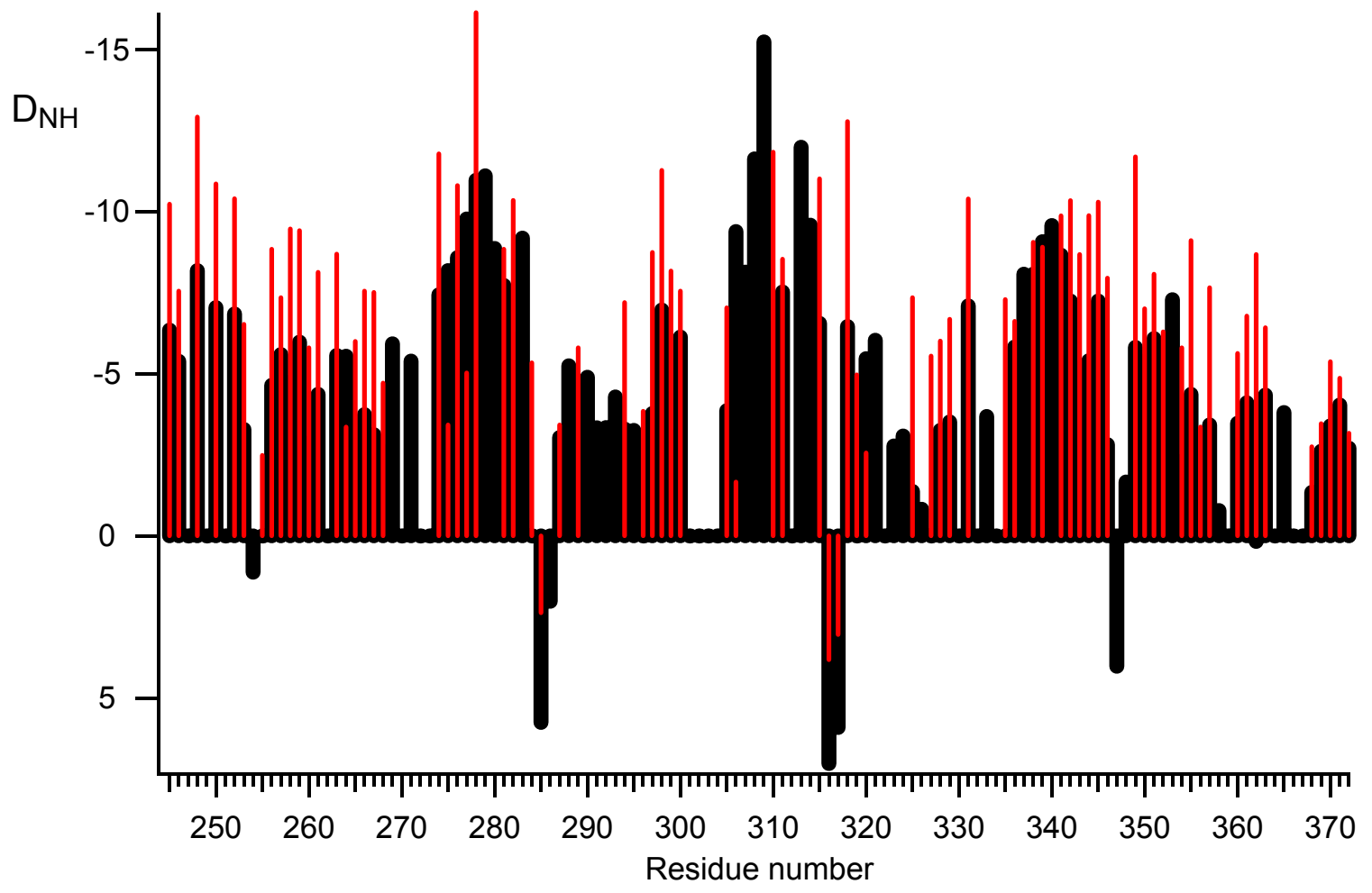

Figure 4

Comparison of measured (red) 3J HNHA couplings with values calculated from the FM ensemble (blue) using known Karplus type relationships (1).

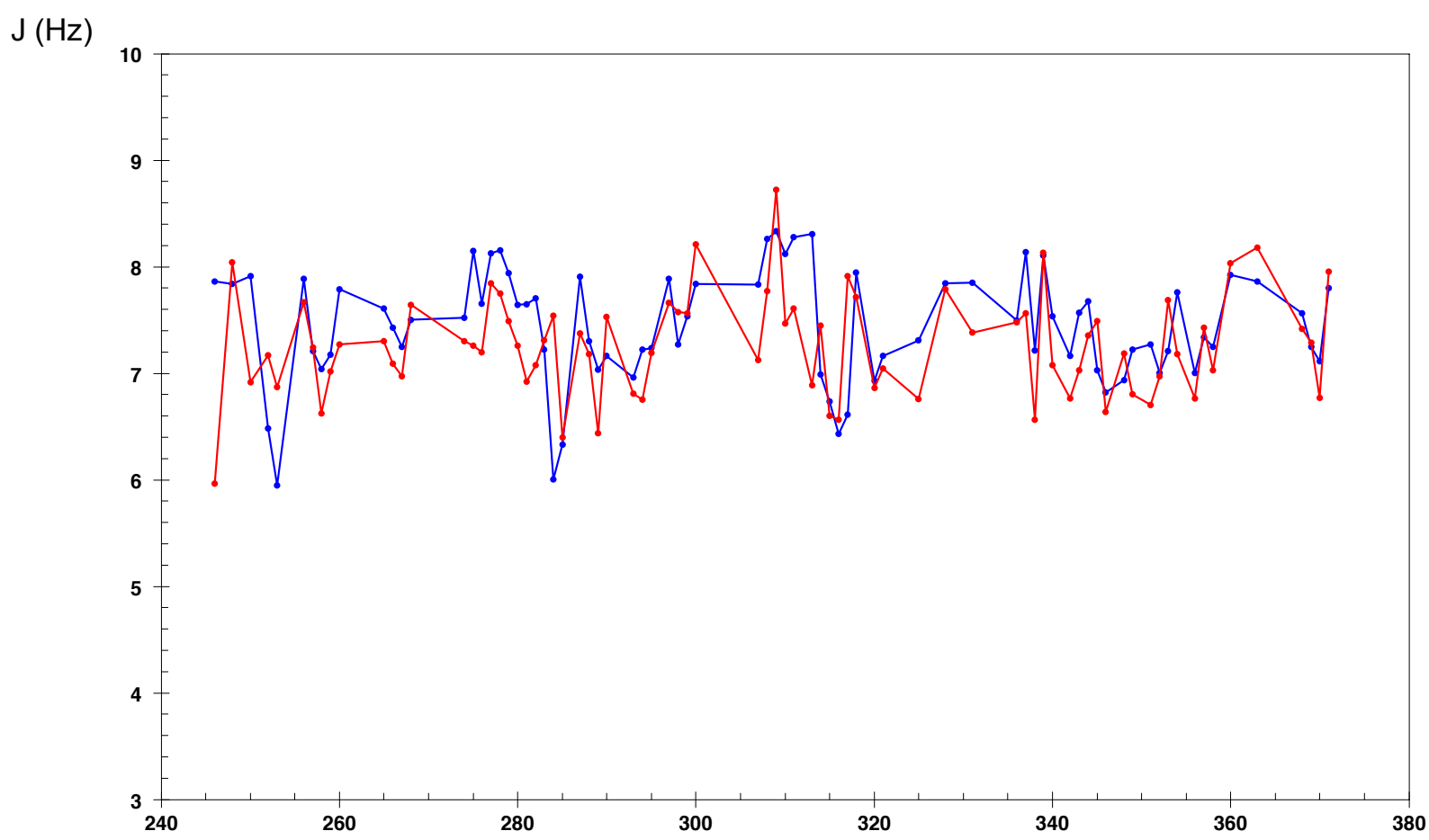

(1) Pardi A, Billeter M, Wüthrich K (1984) J Mol Biol 180 : 741-751 